\title{
Chinese Solution to Solve the Food Safety Problems: Food Safety Campaign
}

\author{
L.YANG, T.F. TAN \& J.M. CHENG* \\ School of Management, Shanxi Medical University, Taiyuan, Shanxi, China \\ K. LI \\ Genaral Workers Hospital of Xishan Coal and Electricity Group (LLC)
}

\begin{abstract}
Food safety concerns people's life and health as well as a nation's wholesome well-being and its stability. With China's increasing engagement in global agricultural markets, food safety is no longer just a domestic issue - it is now a global one. Facing with the repeated food issues, Chinese government have launched the food safety campaign program for many years. By analyzing the development and current implementation situation of Chinese "special campaigns for food safety" in 2004-2014, the paper summarizes its development pattern and regularity, and explores the effective path of solving the food safety issues as a Chinese solution. The positive lessons in solving food safety issue can benefit the food safety management and regulation throughout China and other low or middle income countries.
\end{abstract}

KEYWORD: China; Food industry; Food safety problems; Food safety Campaign; Chinese solution

\section{INTRODUCTION}

Food is essential, food safety is closely related to people's life and health and economic development and social harmony (Wheelock, 1989; China Daily, 2010). Globally, food insecurity played a role in political unrest and conflict (Brinkman \& Hendrix, 2011; Pinstrup-Andersen \& Shimokawa, 2008). Food safety has turned to the main focus of world attention. As a result of eating unsafe food, many people fall ill, disable or die (Miles \& Frewer, 2001). According to WHO, there are up to billions of cases of food-caused diseases all over the world annually (WHO, 2014). Especially in recent years, some repeatedly occurring serious food safety affairs, such as BSE's burst-out in England, the dioxin and other food incidents, have raised the public concerns over the food safety to an unprecedented level. As food industry contines to be a global industry (Stewart et al., 2014), unsafety food turns into a world issue. And, in response to an apparent decline in global food safety, numerous public and private regulatory initiatives have emerged to restore public confidence (Lin, 2014).

In China, food safety accidents have been frequently exposed in recent years, especially in 2011. The food safety problem once again becomes a focus of public concern, such as Shuanghui clenbuterol event, "dyeing steamed bread" event appeared in Hualian and many supermarkets in Shanghai, toxic leek event in Nanyang Henan, milk nitrite poisoning event in Pingliang Gansu, small whitebait soaked by formalin events in Qingdao Shandong, excessive "swollen agent" used in watermelon event, etc (Chen, 2003). Food safety problems seriously threaten people's health, and damage the image of enterprises and even the nation. To improve food safety, in 2012, the State Council of China laid out measures including tighter supervision and harsher punishment for violators and has vowed a "vigous crackdown" on those who endanger food safety (China Daily, 2012). Chinese government has attached great importance to food safety problems, further by strengthening supervision, and trying to solve the food security problems from the sources, ensuring the people's lives and property safety and vital interests. To be fair, China does not lack the strong political will and commitment needed to tackle food safety problems (The Lancet, 2014).

On the whole, as far as China is concerned, for the last 10 years, its food industry, as crucial pillar industry in economy, which has kept the growth rate of over 10 percent from February to June in 2013 (Figure.1), making it the biggest market globally. With China's increasing engagement in global agricultural markets, food safety is no longer just a domestic issue - it is now a global one (The Lancet, 2014). 


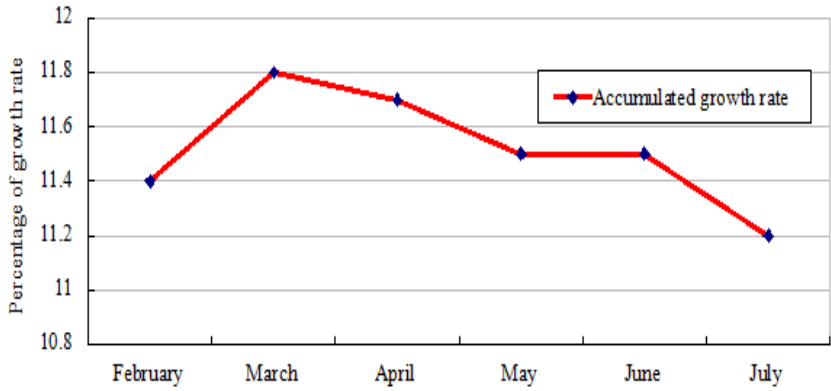

Fig.1. Growth Rate of Value-Added of the Manufacture of Foods (2013.02-07)

http://www.stats.gov.cn/english/Statisticaldata/MonthlyData/

\section{THE INTRICACIES IN FOOD SAFETY ISSUES IN CHINA}

The old Chinese saying "To people, food is heaven" indicates food as the first necessity of man. Each government thus shall take on all its responsibilities to take effective measures to provide quality food and guarantee its citizen's health (Kate et al., 2014; Weigel \& Armijos, 2014). Determined to enforce the food safety and concerned over the public health, recently, both China's central and local governments have laid out various laws and policies. Among these regulations, the Food Safety Law was issued in 2009 and revised in 2014, which reflect the central government's determination in strengthening the supervision and administration of food safety (CCTV News, 2014).

\subsection{The rapid development of China's food industry and the complexity of food safety supervision and administration}

Paralleled with its economy boom, China's food industry has been prospering for late 20 years, with its growth far ahead of that of GDP, especially for the manufacture of foods. Admit it or not, on the other hand, there is still a huge gap between China and some developed countries in the level of the food industry, and the too rapid development of food industry in China attributes to its instability.

Living standards have thus risen across the Chinese population-per-person income has increased by nine times from 1990 to 2008 (Economy Watch, 2010). In 2011, China's Engel's coefficient, which measures the proportion of income spent on food, has improved to $36.3 \%$ (urban) and $40.4 \%$ (rural) (Ma, 2012).

Now, China is in a very phase, in which, the structure of food consumption is being transferred and the demand for processed food is being accelerated in China. In the future, given this consistent development, the food consumption and demand in China will focus on the food's quality, safety, nutrition, variety and convenience rather than quantity. In the meanwhile, the increasingly intensifying food safety problems will affect the stability and harmony of the whole society, especially for the developing country (Akhtar, 2015).

The food safety issue has been a broad and serious subject that so many respects are inevitably involved. It ranges from the plant-based food to animal food, and covers the processes such as food production, processing, planting and breeding, business flow, food consumption etc. It relates to multiple disciplines and technologies including sciences, arts, engineering, medicine, management, horticulture, traditional analysis and latest bio techniques and so on. It involves the large number and diversity of food producers - most being small companies-makes it difficult to maintain high safety standards for all products (The Lancet, 2012). The food safety management system is multilayered, with national, provincial, and local levels and its administrative employment is a very sophisticated operation, through which a series of different departments including that of drug supervision, agriculture, QC, trade and commerce, hygiene are requested to be liaised with each other. Hence, its social influences are closely associated with the public awareness, education, consumptive level, all of which account for the complicatedness, urgency, difficulties underlying in food issues in China.

\subsection{The synchronicity between the social governance capability of Chinese government and the judgment and expectancy of the people}

In recent three decades, China has always developed in the way beyond its inherent capacity. It has overtaken Japan, becoming the second largest economic entity, in 2010. Successfully hosted the Olympic Games and the world expo and the Asian games, a series of international large-scale activities also means the social expectation and the pressure of government governance have been further intensified. As a developing country, China has made great progress in food safety (Wu et al., 2010).

It wasn't long for China from solving the problem of adequate food and clothing to pursuing the food safety and quality, so was China's food industry developing from its beginning to regulated situation, as well as market-oriented economy developing from promoting market to regulating its principal part. Rapid industrialisation and modernisation in China are having profound effects on food supply and food safety (Hon-Ming et al., 2013). With time went by, some food safety problems that need to be solved will gradually come out.

The realistic perception and evaluation is always associated with the expectation form society. Chinese food safety problems are continuously exposed by the news media, in some degrees, it 
indicates that media inspects the economic development and social civilization in China, which is a representation that Chinese society is making progress, and China longs for the equal standards and more safe food as developed countries. People in China pursue from eating enough to eating well, which is a historical transformation in the process of Chinese development. In recent years, intensive management has been an important method of strengthening food safety. The experience has proved that the method to deal with China's food safety situation is practical and necessary.

\section{FOOD SAFETY CAMPAIGN PROGRAM --- THE MANAGEMENT APPROACH FITTING CHINA'S REALITY}

Food safety campaign, aming to slove the repeated food safety problems in China with concentrating the manpower and material resources in a short period, has been launched by Chinese government for many years. The nationwide food safety campaign is aimed at reshaping the entire food industry, and the focus is currently on illegal use of food additives (China Daily, 2011). From 2004, Chinese government had launched many food safety regulation actions, but the food safety campaign truly started in 2009 and continued annually. The food safety campaign mianly focus on promoting food safety awareness among the public, the prominent issues of food additives, edible farm products, food production processing, food circulation and import and export, livestock slaughter, the catering industry and health supplements industry, among others (Xinhuanet, 2012; China Daily, 2010).

In China, in the course of the economic and social transformation, the problems or conflicts underlying a series of procedures all through the food chain and in the food industry tend to get more disclosed. Such procedures include breeding and planting, processing and manufacturing, marketing and consumption. The flaws in food safety supervision system, legislations, relevant standards etc. stand out as well. Some scandals, such as, toxic milk powder in Fuyang, rotten pet food exported to Europe, "sudan red" food poisoning, "melamine milk", and the incident of toxic dumpling exported to Japan etc, reflect the defects in Chin's food quality control. In addition, increases in food prices have been found to strongly exacerbate the risk of political unrest and conflicts (Arezkiand, 2011; Bellemare 2011; Berazneva \& Lee 2013). Targeting against the food problems, starting from 2009, the government has launched the Campaign program nationwide every year (Table 1).
Table 1. Food Safety Campaign Program

\begin{tabular}{|l|l|}
\hline Time & Content Isuued \\
\hline 2004 & The Guidance of Food Safety Campaign Project \\
\hline 2005 & The Food and Drugs Control Project \\
\hline 2006 & The Conduction Plan on Food Safety Campaign \\
\hline 2007 & Food Safety Campaign Program \\
\hline 2007 & Product Quality Control and Food Safety Campaign Plan \\
\hline 2008 & $\begin{array}{l}\text { Crack Down on Illegal Non-edible Substance and } \\
\text { Addictive Abuse }\end{array}$ \\
\hline 2009 & Measures to Enforce Food Safety \\
\hline 2010 & Improvement on Food Safety \\
\hline 2011 & Arrangements for important work on Food Safety \\
\hline 2012 & the key work schedule about food safety \\
\hline 2013 & the key work schedule about food safety \\
\hline 2014 & the key work schedule about food safety \\
\hline
\end{tabular}

source: http://www.gov.cn/

From 2011, Chinese government have continuously required strengthening daily regulation, strengthening food safety regulation, cracking down on the crimes of food safety, eliminating the hidden problems, and perfecting regulation system and have attached more and more importance to food safety (the State Council, 2011; the State Council 2012; the State Council, 2013; the State Coucil, 2014). The special food safety regulation action opens a new chapter. Tainted by the food scandals, aiming at improving the food safety and standardizing the whole food market, the Campaign strives for resolving food concerns in a great array of fields, covering planting, breeding, manufacturing, processing, consumption, trade etc.

\section{RETROSPECT---THE REALISTIC CHOICE OF CHINA'S FOOD SAFETY CAMPAIGN}

Historically, food security has played a crucial role in public health in China (Campbell \& Campbell, 2006; Kantha, 1990). However, the general social resources, in this currently booming yet developing country, will still have to remain relatively deficient for quite a long time, which will lead to the loss of major resources. Consequently, the physical implementation of the regular administration will necessarily be affected or even failed. To respond to such defects in the realistic construction, more importantly, to carry on the typical "state order" characterizing China's political system, here it comes the so-called Campaign into being.

During the Campaign, the government departments of supervision and administration may take drastic measures within their jurisdiction towards some particular area in food, like planting and breeding, manufacturing and processing, operation flow and consumption, import and export trade. They also focus on maintaining the food 
marketing order and cracking down all illegal acts. As a result, some positive immediate effects can be seen, thus the need to guarantee the food safety is met for a certain period. Only at that time, would the above-mentioned departments have to withdraw their intervention from the campaign considering the budget. However, the achieved effects will prompt the relevant administrations to reinforce such approach over and over again. Under the present sociological and economic circumstances in China, the enforcement of the Campaign is definitely placed above all other regular supervision and management so that its ostensible result is attained.

Admittedly, the enhanced performance of the Campaign, with highest priority and most powerful fulfillment, has achieved some noticeable success within a brief stage. However, the effects, with its transience, are not a final or thorough resolution of the whole issue. Once the trial period is over, all the problems will resume or even get worse. Hence, all through the process of the Campaign, some specific plans and measures to guarantee the smooth performance need to be worked out. What's more, the long-term goal and relevant mechanisms also need to be established.

In essence, therefore, to perform the regular administration under state supervision, rather than this tentative form of campaign, the economy needs to be greatly boomed with sufficient administrative resources and well-developed infrastructure. Only by the time China's legal and political system gets perfected, the Campaign will be in the event replaced by another feasible alternative.

\section{CONCLUSION}

The food safety situation in China remains severe. The vast size of China's food production and consumption enterprises, along with the country's global economic importance, make China's food supply and food safety issues of major interest to international markets and trading partners (HonMing et al., 2013).

To solve the food issues in China radically, firstly, the food safety legal system should be improved. The Chinese Government has made tremendous efforts to reform food safety laws as part of a long evolving process (Song, 2011). We should clear, supplement and improve our existing laws, rules, standards and norms in all aspects from each aspect of legislation, enforcement and observance of the laws. On these bases we can construct a unified and orderly legal chain in order to overcome the defects of relatively dispersive terms caused by sectional legislation and fill the gap of legal supervision.

Secondly, we should integrate and re-layout supervision subjects, enhance the legitimacy and coordination of enforcement, eliminate the overlap, fill the gap between agencies, improve the food safety regulatory ability, and finally establish and improve the standard system of food safety, the market access rules, authentication system, traceability system and recall system; at the same time, we should strengthen the research and development of core technology, such as risk analysis, the test and detection, food safety prewarning, etc.

Thirdly, the economic regulation can achieve the market supervision of food safety mainly though some economic tools, such as market price, credit, property, information and the consumer price index (CPI). First, we should devote great efforts to boost the construction of the food enterprise credit mechanism, which can make food companies to consciously abide by Good Manufacturing Practice (GMP), and carry out Hazard Analysis Critical Control Point (HACCP). Second, the government should play its role in guiding market, defining and protecting enterprise property rights and taking some necessary measures to guide and support food enterprises.

Finally, the social forces include the news media and the third department organizations such as industry organizations, intermediary organizations and autonomous organizations. Give full play to the role of the industry association to guide scientific and rational consumption. Strengthen the industrial self-regulation through the industry associations to enhance the overall industry level. Establish the authoritative third party testing institutions and certification bodies to optimize the social detection resources. Strengthen the food safety education to the public by using the education and consensus supervision functions of news media actively.

Under the special social situation, the special campaign is a sports-style campaign. The campaign of food safety is an effective method to deal with Chinese food safety problems in a short time. But, it should not be used frequently. The final method should be based upon the top-level design, and we should solve the problems by improving the food safety inspection mechanism and building a good social atmosphere. Generally speaking, by respecting history, taking down-to-earth approaches and having faith in future, the effective resolution of food issues in China, though takes efforts as well as time, in the event will be accomplished.

\section{CORRESPONDING AUTHOR}

J.M. Cheng, LLM, PhD, is an Associate Professor of Health Service in the School of Management, Shanxi Medical University. His research interests include public health policy, public health service, and global food safety (E-mail: 72-87@163.com). 
Programme: Project of Innovation in Postgraduate Education of Shanxi Province (NO. 20142036)

\section{REFERENCES}

[1] Akhtar S., 2015. Food safety challenges--a Pakistan's perspective. Crit Rev Food Sci Nutr. 55 (2), 219-26.

[2] Arezki, R. \& Brückner, M., 2011. Food prices, Conflict and Democratic Change. International Monetary Fund Working Paper No. 1162. International Monetary Fund, Washington, DC.

[3] Bellemare, M., 2011. Rising food prices, Food Price Volatility, and Political Unrest. MPRA Paper No. 31888. June 2011.

[4] Berazneva, J. \& Lee, D.R., 2013. Explaining the African food riots of 2007-2008: an empirical analysis. Food Pol. $39,28-39$.

[5] Brinkman, H.-J. \& Hendrix, C.S., 2011. Food Insecurity and Violent Conflict: Causes, Consequences, and Addressing the Challenges. Occasional Paper No. 24. World Food Programme, Rome.

[6] Campbell TC \& Campbell TM, 2006. The China study. Dallas, TX: Benbella Books.

[7] Chen Junshi, 2003. Food safety - China's major public health problem. China J Epidemiol. 24 (8), 649-650.

[8] China income, China national income. Economy Watch, June 30, 2010.

[9] China vows new food safety campaign (Xinhua). China Daily, 2010, February 10. Retrieved from < http://www.chinadaily.com.cn/201002/10/content_9453301.htm>.

[10] China's food safety campaign gathers momentum (Xinhua). China Daily, 2011, July 17. Retrieved from <http://www.chinadaily.com.cn/china/201107/17/content_12918913.htm>.

[11] Chinese lawmakers to review food safety law. CCTV News, 2014, June 23. Retrieved from <http://english.cntv.cn/2014/06/23/VIDE1403516399975 808.shtml>. doi: 10.1080/10408398.2011.650801.

[12] Food safety campaign kicks off in China. Xinhuanet, 2012, June 12. Retieved from < http://news.xinhuanet.com/english/video/201206/12/c_131647037.htm>.

[13] Hon-Ming Lam, Justin Remais, Ming-Chiu Fung, Liqing Xu \& Samuel Sai-Ming Sun, 2013. Food supply and food safety issues in China. Lancet. 381(9882), $2044-2053$.

[14] Kantha SS, 1990. Nutrition and health in China, 1949 to 1989. Prog Food Nutr Sci. 14, 93-137.

[15] Kate K, Negi S \& Kalagnanam J., 2014. Monitoring food safety violation reports from internet forums. Stud Health Technol Inform. 205,1090-4.
[16] Lin CF, 2014. Public-private interactions in global food safety governance. Food Drug Law J. 69 (2), 143-60.

[17] Ma MT. Rebounce of Engel's coefficient in urban households in the previous year. The Beijing News June 20, 2012. (Beijing), section B05 (in Chinese).

[18] Miles S \& Frewer LJ, 2001. Investigating specific concerns about different food hazard. Food Quality \& Preference. 12, 47-61.

[19] Pinstrup-Andersen, P. \& Shimokawa, S., 2008. Do poverty and poor health and nutrition increase the risk of armed conflict onset? Food Pol. 33, 513-520.

[20] Song H, 2011. A study on food safety standard law in China. J Public Admin. 2, 30-50. (in Chinese).

[21] State Council improves food safety. China Daily, 2012, June $14 . \quad$ Retrieved from $<$ http://www.chinadaily.com.cn/china/201206/14/content_15500104.htm>.

[22] Stewart D, Kennedy A \& Pavel A, 2014. Beyond nutrition and agriculture policy: collaborating for a food policy. $\mathrm{Br}$ $J$ Nutr. 2014 Oct; 112 Suppl 2:S65-74. doi: $10.1017 / \mathrm{S} 000711451400230 \mathrm{X}$

[23] The Lancet, 2012. Food safety in China: a long way to go. Lancet. 380 (9837), 75.

[24] The Lancet, 2014. China's food safety: a continuing global problem. Lancet. 384 (9941), 377.

[25] The State Council, 2011. The 2011 key work schedule about food safety. Accessed November 2014. <http://www.gov.cn/zwgk/201103/25/content_1831345.htm>.

[26] The State Council, 2012. The 2012 key work schedule about food safety. Accessed November 2014. <http://www.gov.cn/zwgk/201203/02/content_2079199.htm>.

[27] The State Council, 2013. The 2013 key work schedule about food safety. Accessed November 2014. <http://www.gov.cn/zwgk/201304/16/content_2378952.htm>.

[28] The State Council, 2014. The 2014 key work schedule about food safety. Accessed November 2014. $<$ http://www.gov.cn/xinwen/201405/27/content_2687816.htm>.

[29] Weigel MM \& Armijos MM, 2014. Food Insufficiency in the Households of Reproductive-Age Ecuadorian Women: Association with Food and Nutritional Status Indicators. Ecol Food Nutr. 27,1-23. [Epub ahead of print]

[30] Wheelock V, 1989. Food safety in perspective. British Food Journal. 93, 31-36.

[31] WHO(World Health Organization). 2012. Food safety. Accessed $\quad$ November 2014. $<$ http://www.who.int/topics/food_safety/en/>.

[32] Wu, X. L., Wu, H., Xia, L. X., Ji, K. M., Liu, Z. G. \& Chen, J. J., 2010. Socio-technical innovations for total food chain safety during the 2008 Beijing Olympics and Paralympics and beyond. Trends Food Science and Technology, 21, 44e51. 